This item was submitted to Loughborough's Research Repository by the author.

Items in Figshare are protected by copyright, with all rights reserved, unless otherwise indicated.

\title{
Structural studies of metal ligand complexes by ion mobility-mass spectrometry
}

\section{PLEASE CITE THE PUBLISHED VERSION}

http://dx.doi.org/10.1007/s12127-013-0122-8

\section{PUBLISHER}

(c) Springer Verlag

\section{VERSION}

AM (Accepted Manuscript)

\section{PUBLISHER STATEMENT}

This work is made available according to the conditions of the Creative Commons Attribution-NonCommercialNoDerivatives 4.0 International (CC BY-NC-ND 4.0) licence. Full details of this licence are available at: https://creativecommons.org/licenses/by-nc-nd/4.0/

\section{LICENCE}

CC BY-NC-ND 4.0

\section{REPOSITORY RECORD}

Wright, Victoria E., Fernando Castro-Gomez, Ewa Jurneczko, James C. Reynolds, Andrew M. Poulton, Steven D.R. Christie, Perdita Barran, Carles Bo, and Colin S. Creaser. 2019. "Structural Studies of Metal Ligand Complexes by Ion Mobility-mass Spectrometry”. figshare. https://hdl.handle.net/2134/15924. 


\section{Structural Studies of Metal Ligand Complexes by Ion Mobility-Mass Spectrometry}

Victoria E. Wright ${ }^{\mathrm{a}}$, Fernando Castro-Gómez ${ }^{\mathrm{b}}$, Ewa Jurneczko ${ }^{\mathrm{c}}$, James C. Reynolds ${ }^{\mathrm{a}}$, Andrew Poulton ${ }^{\mathrm{d}}$, Steven D. R. Christie ${ }^{\mathrm{a}}$, Perdita Barran ${ }^{\mathrm{b}}$, Carles Bo ${ }^{\mathrm{b}, \mathrm{e}}$, Colin S. Creaser ${ }^{\mathrm{a}}$

${ }^{a}$ Centre for Analytical Science, Department of Chemistry, Loughborough University, Loughborough, Leicestershire, LE11 3TU, UK

${ }^{b}$ Institute of Chemical Research of Catalonia (ICIQ), Tarragona, Spain

${ }^{c}$ School of Chemistry, University of Edinburgh, Joseph Black Building, The King's Buildings,

West Mains Road, Edinburgh EH9 3JJ

${ }^{d}$ Pharmaceutical Development, AstraZeneca, Macclesfield, Cheshire, UK.

${ }^{e}$ Departament de Química Física i Inorgànica. Universitat Rovira i Virgili, Tarragona, Spain

* Corresponding author:

Email.c.s.creaser@lboro.ac.uk

Tel. +44 (0)1509 222552

Fax. $+44(0) 1509223925$ 


\section{Abstract}

Collision cross sections (CCS) have been measured for three salen ligands, and their complexes with copper and zinc using travelling-wave ion mobility-mass spectrometry (TWIMS) and drift tube ion mobility-mass spectrometry (DTIMS), allowing a comparative size evaluation of the ligands and complexes. CCS measurements using TWIMS were determined using peptide and TAAH calibration standards. TWIMS measurements gave significantly larger CCS than DTIMS in helium, by $9 \%$ for TAAH standards and $4 \%$ for peptide standards, indicating that the choice of calibration standards is important in ensuring the accuracy of TWIMS-derived CCS measurements. Repeatability data for TWIMS was obtained for inter- and intra-day studies with mean RSDs of $1.1 \%$ and $0.8 \%$, respectively. The CCS data obtained from IM-MS measurements are compared to CCS values obtained via the projection approximation, the exact hard spheres method and the trajectory method from X-ray coordinates and modelled structures using density functional theory (DFT) based methods. 


\section{Introduction}

In ion mobility spectrometry, ions are injected into a drift cell with an electric field $(E)$ and containing a buffer gas. The drift velocity $\left(v_{d}\right)$ of a given ion in the presence of an electric field $(E)$ is dependent on the mobility $(K)$, of the ion (Eqn.1). The mobility is determined by the reduced mass, charge and collision cross section (CCS).

$$
v_{d}=K E \quad \text { Eqn.1 }
$$

In a linear DTIMS drift cell with a static field, the CCS can be determined directly from the mobility of an ion using Eqn.2. ${ }^{1}$

$$
K=\left(\frac{3 q}{16 N}\right)\left(\frac{2 \pi}{\mu k T_{e f f}}\right)^{1 / 2}\left(\frac{1}{\Omega}\right) \quad \text { Eqn.2 }
$$

where $q$ is the charge of an ion, $N$ is the gas density number (proportional to pressure), $\mathrm{k}$ is the Boltzmann's constant, $\mu$ is the reduced mass of the ion, $T_{\text {eff }}$ is the effective temperature of the ion, and $\Omega$ is the cross section of the ion.

Ion mobility hyphenated with mass spectrometry (IM-MS) provides added specificity for analysis of target analytes; in recent years, travelling wave IM-MS (TWIMS) ${ }^{2}$ has also been used to determine CCS. ${ }^{3-11}$ The principles of TWIMS have been described in more detail elsewhere. ${ }^{2}$ However, in summary, the drift cell contains paired electrodes that create a pulsed voltage which carries the ions through the drift cell as a travelling wave.

In a TWIMS drift tube the relationship between drift time and mobility is non-linear and therefore standards with known CCS, that have been previously determined using a linear DTIMS drift cell, are needed to calibrate the system. A graph is plotted of known CCS modified to account for reduced mass and charge, against effective drift time and from this 
the CCS of the analytes can be determined. Calibrants have included peptides ${ }^{11,12,13}$, tetraalkylammonium halides (TAAHs), and pharmaceutical compounds ${ }^{5}$ with structures that are usually different to that of the analyte ion under investigation. There are several reports on the application of this method to the study of metabolites, ${ }^{4,5}$ proteins and peptides. ${ }^{6-10}$

Arenes and adamantanes have been studied by TWIMS and their experimental and theoretical CCS investigated. ${ }^{11}$ Napthalene, phenanthrene and pyrene were analysed in helium and nitrogen drift gases to determine CCS, which were then compared to modelled data. The experimentally determined CCS were similar for both drift gases indicating low polarisability effects between the analytes and drift gas as a result of the rigidness and low functionality of these molecules.

The study of metal containing ions by IM-MS has been reported using linear drift tubes and TWIMS. The CCS of biological molecules binding small metals such as the alkali metals ${ }^{14-17}$ as well as transition metals, ${ }^{18-23}$ have been widely studied. The CCS of cationised polystyrene with $\mathrm{Li}^{+}, \mathrm{Na}^{+}, \mathrm{Cu}^{+}$and $\mathrm{Ag}^{+}$have also been reported. ${ }^{24}$ In contrast, little work has been carried out on small non-biological metal-ligand complexes containing transition metals. Ruthenium anti-cancer complexes have been studied and their CCS determined using TWIMS-MS. ${ }^{12,13}$ The CCS were compared to theoretical values calculated from x-ray structures and models using MOBCAL ${ }^{25}$ projection approximation, (PA), exact hard sphere scattering, (EHSS) and trajectory, (TM) methods, and a Waters CCS calculator. ${ }^{13}$ The measured CCS for the ruthenium complexes ${ }^{12}$ showed good agreement with the PA and TM approximations. However, the EHSS method overestimated the CCS, although the smallest of the ruthenium complex showed good correlation with the PA, TM and EHSS methods. The Waters algorithm was also used to calculate the CCS using x-ray coordinates producing results similar to those obtained using MOBCAL, modelled structures and the experimental data. 
This suggests that the CCS obtained from x-ray data may provide a good representation of the structures of metal complexes in the gas-phase present in the drift cell.

In this paper, we report the analysis of metal-ligand complexes of copper and zinc using IMMS. The CCS were measured in a static field drift tube and by TWIMS using peptide and TAAH calibrants. Measured CCS are compared to theoretical CCS obtained from x-ray and modelled data. 


\section{Experimental}

\section{Materials}

HPLC grade methanol, water and the peptide standards; (Glycine) $)_{2},(\text { Alanine })_{3},(\text { Alanine })_{5}$, (Lysine) $)_{4}$, (Phenylalanine) $)_{4}$, (Phenylalanine $)_{5}$ were purchased from Fisher Scientific (Loughborough, UK). Lutidine and the following (TAAHs): tetraethylammonium bromide, tetrapropylammonium iodide, tetrabutylammonium iodide, tetrahexylammonium iodide, tetraoctylammonium bromide, tetradodecylammonium bromide were obtained from SigmaAldrich (Gillingham, UK) and tetrapentylammonium bromide, tetraheptylammonium bromide were obtained from Fisher Scientific (Loughborough, UK).

\section{Ligand synthesis}

Ligand 1: trans-1,2-diaminecyclohexane $(0.49 \mathrm{~g}, 0.0043 \mathrm{~mol})$ was weighed in a $25 \mathrm{~mL}$ round-bottom flask and dissolved in methanol (2 mL). Salicylaldehyde (1 g, $0.0081 \mathrm{~mol})$ was added. The mixture was stirred for $1 \mathrm{hr}$. The yellow precipitate formed was filtered and then weighed and placed in a vial. It was then recrystalised from hot methanol.

Ligand 2: phenylenediamine $(0.51 \mathrm{~g}, 0.0046 \mathrm{~mol})$ was weighed in a $25 \mathrm{~mL}$ round-bottom flask and dissolved in methanol $(5.5 \mathrm{~mL})$. Salicylaldehyde $(1 \mathrm{~g}, 0.0081 \mathrm{~mol})$ in methanol $(0.7$ $\mathrm{mL}$ ) was added to the solution. The mixture was stirred for $2 \mathrm{hr} 15 \mathrm{~min}$. The solution turned yellow after $3 \mathrm{~min}$ of stirring. The yellow precipitate formed was filtered and placed in a dessicator for $1 \mathrm{hr}$ and then weighed and placed in a vial. It was then recrystalised from hot methanol.

Ligand 3: ethylenediamine $(0.57 \mathrm{~g}, 0.0095 \mathrm{~mol})$ was weighed in a $25 \mathrm{~mL}$ round-bottom flask and dissolved in methanol $(15 \mathrm{~mL})$. Salicylaldehyde $(1.78 \mathrm{~g}, 0.0146 \mathrm{~mol})$ was added and the 
solution stirred for $1 \mathrm{hr} 30 \mathrm{~min}$. The yellow precipitate formed was filtered and recrystalised from hot methanol.

Ligands 1-3 were verified by NMR (supplementary information, S1).

\section{Sample Preparation}

The ligands and metal-ligand complexes were prepared as $1 \mathrm{nmol} / \mu \mathrm{L}$ solutions in 90:10 methanol:water. Ligands 1, 2 and 3 and their copper complexes were diluted (1:10) prior to analysis. The ligand:zinc complexes were diluted; L1:Zn (1:10), L2:Zn (1:20), L3:Zn (1:5) prior to analysis.

\section{Ion mobility - Mass Spectrometry}

TWIMS Analyses were performed using a Waters Synapt HDMS spectrometer (Waters Corporation, Manchester, UK), with a hybrid quadrupole/ion mobility/orthogonal acceleration time-of-flight (oa-ToF) geometry controlled by Waters MassLynx operating sofware. Samples were introduced into the electrospray ionisation source via direct infusion methanol water (90:10) at a flow rate of $5 \mu \mathrm{L} / \mathrm{min}$. The source and desolvation temperatures were set to $120^{\circ} \mathrm{C}$ and $250^{\circ} \mathrm{C}$, respectively, gas flow $\left(\mathrm{N}_{2}\right)$ rates were set to $20 \mathrm{~L} / \mathrm{h}$ and $600 \mathrm{~L} / \mathrm{h}$ respectively. The tri-wave drift cell conditions were set at $30 \mathrm{~mL} / \mathrm{min}$ drift gas $\left(\mathrm{N}_{2}\right)$ with a ramped traveling wave height of $8-18 \mathrm{~V}$ and a velocity of $300 \mathrm{~m} / \mathrm{s}$. The acquired IM-MS data were processed using DriftScope and MassLynx 4.1 (Waters, Manchester, UK). CCS were determined using peptide and TAAH standards of known CCS in helium. The calibration standards were analysed by IM-MS and used to produce a calibration curve after the data were corrected for the non-linear electric field in the TWIMS system. The CCS of the free ligands and metal complexes were then determined from the graph using Eqn. $3^{26}$. 


$$
\Omega_{(\mathrm{T}-\text { wave })}^{\prime}=\mathrm{t}_{\mathrm{d}}{ }^{\mathrm{B}} \times \mathrm{A} \times \mathrm{q} \times\left(\frac{1}{\mathrm{M}_{\text {ion }}} \times \frac{1}{\mathrm{M}_{\text {gas }}}\right)^{1 / 2}
$$

Where $\Omega$ ' is the determined collision cross section, $t_{d}$ " is the effective drift time corrected to account for instrument offsets, parameter B compensates for the non-linear effect of the TWIMS system and parameter A for the temperature, pressure and electric field conditions, $\mathrm{q}$ is the charge and $\mathrm{M}$ is the mass.

Drift tube analyses were performed in helium using an in-house modified commercial quadrupole time-of-flight instrument (Micromass UK Ltd., Manchester, UK) by the addition of a chamber containing a linear, $5.1 \mathrm{~cm}$ copper drift cell and ancillary ion optics. ${ }^{27}$ Ions were produced by positive nESI ionisation using a Z-spray source, within a spray voltage range of $1.2-1.8 \mathrm{kV}$ and a source temperature of $80^{\circ} \mathrm{C}$. Source pressure was optimized for signal transmission. nESI spray tips were prepared in-house with a micropipette puller (Fleming/Brown model P-97, Sutter Instruments Co., USA) using 4" $1.2 \mathrm{~mm}$ thin wall glass capillaries (World Precision Instruments, Inc., USA). The drift cell was filled with helium buffer gas (CP grade, 99.999\% purity, BOC Specialty Gases Ltd, Guildford, UK) and the pressure was measured using a Baratron (MKS Instruments). The temperature of the drift cell was closely monitored and recorded. The electric field across the cell was varied from $12-2$ V.cm ${ }^{-1}$. Ion arrival time distributions were recorded by synchronisation of the release of ions into the drift cell with mass spectral acquisition. Using the theory described above, the mobility of the ion of interest was obtained from a plot of average arrival time versus pressure/temperature and from this the rotationally-averaged CCS for each resolvable species at a given charge state were obtained using Eqn. 2 above. 
Theoretical assessment of CCS

MOBCAL was used to theoretically calculate the CCS by applying three algorithms: the projection approximation (PA), ${ }^{28}$ the exact hard sphere scattering method (EHSS) ${ }^{29}$ and the trajectory simulation method $(\mathrm{TM})^{30}$. Molecular structures were taken either from X-ray crystallographic data (neutral ligands and complexes) or optimized using a Density Functional Theory (DFT) based method (protonated ligands and complexes). Helium parameters were assumed when carrying out MOBCAL calculations. For $\mathrm{H}, \mathrm{C}, \mathrm{N}$, and $\mathrm{O}$ atoms, the 12-6 default parameters in $\mathrm{MOBCAL}^{30}$ were considered as well as recently developed sets from Siu et al. ${ }^{31}$ and from Campuzano et al. ${ }^{5}$ For $\mathrm{Cu}$ and $\mathrm{Zn}$ atoms, the 12-6 parameters for silicon were used. For all the atoms, charge-induced dipole interactions were included from Mulliken atomic charges computed at the DFT level.

DFT calculations were performed using the GAUSSIAN09 ${ }^{32}$ package within B3LYP formalism. The standard 6-31G(d,p) basis set was used to describe the $\mathrm{H}, \mathrm{C}, \mathrm{N}$ and $\mathrm{O}$ atoms. The relativistic effective core pseudo potential LANL2DZ was used, together with its associated basis set, for $\mathrm{Zn}$ and $\mathrm{Cu}$. Full geometry optimisations were performed. The nature of the stationary points encountered has been characterised by harmonic vibrational frequencies analysis. The Fortran77 MOBCAL code were compiled and optimised using the Portland PGFORTRAN Compiler. Some scripts were built for running calculations in batches. 


\section{$\underline{\text { Results and Discussion }}$}

Drift tube ion mobility-mass spectrometry (DTIMS) and TWIMS-MS have been used to determine CCS for three salen ligands, L1-L3 (Fig. 1), and their metal complexes with copper (II) and zinc (II) under low field conditions. The ligands and metal complexes form singly charged ions of the type $\left.\left[\mathrm{Metal}^{2+}+\mathrm{L}-\mathrm{H}^{+}\right)\right]^{+}$in the electrospray (ESI) source, equivalent to a protonated version of the neutral metal complex with the proton located on a nitrogen or oxygen atom. Modelling studies reveal the most stable structure to be those with the proton on the most basic oxygen site.

CCS for the ligands and complexes determined using DTIMS and TWIMS are given in Table 1. Peptide or TAAH standards were used to calibrate the TWIMS drift tube data, because of the non-linear relationship between drift time and mobility. Peptide CCS measured in helium were taken from the Clemmer database ${ }^{33}$. TAAH CCS were measured in helium using DTIMS as part of this study (see supplementary information, S2) and agree with previously reported data. ${ }^{5,31}$ The standards were used to create a calibration curve from which the CCS of the analytes were determined. The inter- and intra-day reproducibility (\%RSD) of the TWIMS measurements were $1.1 \%$ and $0.8 \%$, respectively. The TWIMS ion mobility spectra for $\mathrm{L} 1, \mathrm{~L} 1 \mathrm{Cu}$ and $\mathrm{L} 1 \mathrm{Zn}$ are shown in Figure 2.

The CCS of the protonated ligands measured by TWIMS and DTIMS decrease in size in the order L1 > L2 > L3 (see Table 1). L1 has a trans conformation of the cyclohexane ring compared to the planar benzene ring giving it the largest CCS. Ligand 3 has a smaller CCS than ligands 1 and 2 due the absence of an aromatic ring. The CCS of the free ligands and the metal-ligand complexes increase in size in the order $\mathrm{L} \leqslant \mathrm{L}: \mathrm{Cu}<\mathrm{L}: \mathrm{Zn}$, consistent with the a slightly larger ionic radius of $\mathrm{Zn}$ (II) than $\mathrm{Cu}$ (II). 
The CCS for the ligands and metal-ligand complexes from the TWIMS data, calibrated using the two sets of standards showed an average 5\% difference. The CCS determined using the TAAH calibration are systematically larger than the CCS obtained using peptide calibrants. The CCS measured by TWIMS were also larger than the DTIMS CCS measurements; on average by $9 \%$ for the TAAH standards and $4 \%$ for the peptide standards. Campuzano et al. ${ }^{5}$ reported a similar observation for CCS of betamethasone and dexamethasone measured in nitrogen using TWIMS and calibrated with a drug-like calibration mix. This suggests that the conditions in the TWIMS drift cell may generate larger CCS depending on the species being analysed and the calibration process.

The difference between the CCS measured by TWIMS, using TAAH and peptide calibrants, and DTIMS is most likely due to the use of standards with CCS determined in helium to calibrate measurements made in nitrogen in the TWIMS drift cell. This extrapolation provides an approximation of the CCS in helium, but does not fully correct for the compound dependent interaction of the polarisable nitrogen drift gas with the calibrants and the ligands and their metal complexes. ${ }^{11-13,34}$ However, the TWIMS experimental CCS values closely reflect the DTIMS CCS measurements in helium. A further contributing factor may be ion heating in the TWIMS drift tube as a result of the RF ion confinement. Morsa et al. ${ }^{35}$ used a TWIMS drift tube to investigate the effect of experimental TWIMS parameters on the effective temperature of an ion. They used $p$-methoxybenzyl pyridinium as a chemical thermometer and showed that the vibrational effective temperature $\left(\mathrm{T}_{\text {eff,vib }}\right)$ increases with increasing wave height and decreasing velocity and drift gas pressure. The heating effect is expected to be greater for smaller ions than larger ones as larger ions move slower. $\mathrm{T}_{\text {eff,vib }}$ is also greater for ions in a nitrogen drift gas than a helium drift gas at lower ion velocities, 
although at higher velocities helium shows similar effects. ${ }^{35} \mathrm{~T}_{\text {eff }}$ varies from ion to ion and therefore may be different for the ligands, their metal complexes, and the TAAH and peptide calibrants. If ion heating effects are not fully corrected by the calibration process, this may contribute to the variation between CCS determined using TWIMS with TAAH and peptide calibrants and the DTIMS data. $\mathrm{T}_{\text {eff }}$ may also affect ion structure and hence CCS although the significance of these changes are unknown. ${ }^{35}$ The use of calibration standards clearly corrects partially, but not fully for all these factors. An additional effect that will have an influence on both forms of IMS is that of injection energy. Both apparatus, inject ions into a higher pressure region, this can cause conformational change which may be reflected in the measurements, and may be different for each set of calibrants. In this study, the peptide standards, which have very different functionality provide a better estimate of the CCS for the ligands and metal-ligand complexes determined by DTIMS than the TAAHs standards, which form a simple homologous series.

The X-ray structures of the ligands and their metal complexes were obtained from the Crystalweb crystal structure database, and the pdb files were input into the set of codes contained within MOBCAL in order to obtain theoretical CCS (Table 2) using all three MOBCAL methods (PA, EHSS and TM). There was generally good agreement between the PA and TM approximations, allowing for the reproducibility of the measurements. However, the EHSS method overestimates the CCS, which is consistent with previously reported data. ${ }^{12,}$ ${ }^{13}$ Experimental CCS determined by TWIMS using the peptide standards show better correlation with both the PA and TM derived from the $\mathrm{x}$-ray data, than with the data calibrated using the TAAH, with the exception of the free ligands L2 and L3. It should be noted that the CCS derived from the $\mathrm{x}$-ray data suggest that CCS L2 $\geqslant$ L1 $>$ L3, which differs from the order observed experimentally. This may be due to protonation in the gas- 
phase restricting out of plane rotation of the phenol rings, which does not occur in the solid state. The DTIMS experimental data is poorly correlated with both the PA and TM derived CCS from the x-ray structures, showing consistently smaller CCS radius. These observations suggest that CCS derived from x-ray coordinates should be used with caution in structural studies of small ligands and metal-ligand complexes measured by IM-MS.

The geometries of the ligands and their metal complexes were therefore modelled in their protonated gas-phase form by computing the minimum energy isomer by DFT (see supplementary information, S3). MOBCAL was used to calculate the theoretical CCS from the modelled data (Table 2). The PA and TM CCS derived from the modelled data show reasonable agreement with those derived from the x-ray data. The modelled and x-ray results correlate better with the experimental data using the TAAH standards than the peptide standards and DTIMS data. This suggests that MOBCAL overestimates the CCS for these small ions.

The parameters within MOBCAL were optimised using new parameters [CARLAS AND FERNANDO TO ADD BRIEF COMMENT HERE ON THE NEW PARAMETERS USED] obtained from the literature by Siu et $a .^{31}$ and Campuzano et al..$^{5}$ The x-ray and modelled CCS were re-calculated using the new parameters sets (Table 3). The recalculated CCS showed good agreement between the PA and TM approximation for both sets of data. The TM and PA CCS data obtained using the Siu parameters on the x-ray coordinates are within 5 $\AA^{2}$ of the DTIMS experimental data, which is at the upper end of the range for measurement uncertainty. The Campuzano TM optimised data set indicates a slight overestimation of the CCS with the calculated CCS displaying increased correlation with the peptide standard data. 
Figure 3 shows a comparison of the experimental data and the x-ray and modelled data using the Siu parameters, for the L3Cu complex. [VICKY TO CLARIFY WHETHER L2Cu or L3Cu DATA WAS USED IN FIG.3 AND AMEND, AS APPROPRIATE, THE FIGURE, THE TEXT ON PAGE 12 AND THE LEGEND TO THE FIGURE] In contrast to the x-ray data, a comparison of the experimental CCS data against the modelled CCS data calculated using the new parameters displays excellent agreement between the DTIMS PA and TM data using the Siu parameters within $\pm 3 \AA^{2}$. This illustrates the need for refinement of the methods used to calculate CCS from coordinate sets and highlighting the sensitivity of this approach. The peptide data also correlates well with the Siu PA parameter data allowing for the slight (4\%) overestimate for the TWIMS data using the peptide standards. There is poorer correlation between the DTIMS and TWIMS experimental measurements and the TM results using the Campuzano parameters. The presented data demonstrates that the PA and TM calculations with the modified parameters for the modelled structures show better correlation with the experimental data for the ligands and complexes studied than x-ray structures and that TWIMS CCS measurements using peptide standards may be correlated with calculated data for structural studies of low molecular weight metal complexes. 


\section{$\underline{\text { Conclusions }}$}

DTIMS and TWIMS have been used to determine the collision cross sections of ligand species (containing nitrogen and oxygen binding atoms) and their complexes with copper and zinc. TWIMS measurements were carried out in nitrogen, using TAAH and peptide calibration compounds, with reported helium-derived collision cross sections. Intra-day and inter-day reproducibility for the TWIMS collision cross sections gave \% RSDs of less than 2\%. TWIMS measurements gave significantly larger collision cross sections than DTIMS in helium, by $9 \%$ using TAAH calibration and $4 \%$ using peptide calibration, indicating that peptide standards may be better for measurements of small ligands and their metal complexes. The experimental collision cross sections were compared with theoretical cross sections determined using modified MOBCAL calculations from molecular geometries derived from in-silico modelling and x-ray data. CCS data calculated from modelled structures showed a good correlation with experimental CCS measurements made by DTIMS in helium and TWIMS measurements made in nitrogen, when peptide calibrants were used for the TWIMS measurements.

\section{Acknowledgements}

We thank Loughborough University for the award of a studentship to V.E.W and AstraZeneca for financial support. Research support from the ICIQ Foundation, Spanish Ministerio de Economia y Competitividad (MINECO grant CTQ2011-29054-C02-02) and the Generalitat de Catalunya (2009SGR-00259) is gratefully acknowledged. Waters and the BBSRC are acknowledged for the award of a strategic CASE studentship to E.J. The BMSS (British Mass Spectrometry Society) is thanked for proving the funds for a pipette puller enabling the nanospray experiments on the DTIMS. 


\section{$\underline{\text { References }}$}

1. Creaser CS, Bramwell CJ, Noreen S, Hill CA, Thomas CL (2004) Analyst 129:984994.

2. Giles K, Pringle SD, Worthington KR, Little D, Wildgoose JL and Bateman RH (2004) Rapid Comm Mass Spectrom 18:2401-2414.

3. Scarff CA, Snelling JR, Knust MM, Wilkins CL, Scrivens JH, (2012) J Am Chem Soc 134: 9193-9198.

4. Wassvik C, Mortishire-Smith RJ, Tresadern G, Campuzano I, Claereboudt J, (2011) Rapid Comm Mass Spectrom 25:3497-3503.

5. Campuzano I, Bush MF, Robinson CV, Beumont C, Richardson K, Kim H, Kim HI, (2012) Anal Chem 84:1026-1033.

6. Scarff CA, Thalassinos K, Hilton GR and Scrivens JH, (2008) Rapid Comm Mass Spectrom 22:3297-3304.

7. Thalassinos K, Grabenaur M, Slade SE, Hilton GR, Bowers MT and Scrivens JH, (2009) Anal Chem 81:248-254.

8. Salbo R, Bush MF, Naver H, Campuzano I, Robinson CV, Pettersson I, Jørgensen TJD, Haselmann KF, (2012) Rapid Comm Mass Spectrom 26:1181-1193.

9. Michaelevski I, Eisenstein M, Sharon M, (2010) Anal Chem 82:9484-9491.

10. Atmanene C, Petiot-Bécard S, Zeyer D, Dorsselaer AV, Hannah VV, SanlierCianférani S, (2012) Anal Chem 84:4703-4710.

11. Knapman TW, Berryman JT, Campuzano I, Harris SA and Ashcroft AE, (2010) Int J Mass Spectrom 298:17-23.

12. Williams JP, Bugarcic T, Habtemariam A, Giles K, Campuzano I, Rodger PM and Sadler PJ, (2009) J Am Chem Soc Mass Spectrom 20:1119-1122.

13. Williams JP, Lough JA, Campuzano I, Richardson K and Sadler PJ, (2009) Rapid Comm Mass Spectrom 23:3563-3569.

14. Wyttenbach T, Batka JJ, Gidden J and Bowers MT, (1999) Int J Mass Spectrom. 193:143-152. 
15. Wyttenbach T, Witt M and Bowers MT, (2000) J Am Chem Soc 122:3458-3464.

16. Clowers BH and Hill Jr HH, J, (2006) Mass Spectrom 41:339-351.

17. Moision RM and Armentrout PB, (2006) J Phys Chem A 2:3933-3946.

18. Taraszka JA, Li J and Clemmer DE, (2000) J Phys Chem B 104:4545-4551.

19. Leavell MD, Gaucher SP, Leary JA, Taraszka JA and Clemmer DE, (2002) J Am Chem Soc Mass Spectrom 13:284-293.

20. Baker ES, Manard MJ, Gidden J and Bowers MT, (2005) J Phys Chem B 4808-4810.

21. Wyttenbach T, Liu DF and Bowers MT, (2008) J Am Chem Soc 130:5993-6000.

22. Berezovskaya Y, Armstrong CT, Boyle AL, Porrini M, Woolfson DN, Barran PE, (2011), Chem Commun 47:412-414.

23. Chepelin O, Ujma J, Barran PE, Lusby PJ, (2012), Angew Chem Int 51:4194-4197.

24. Gidden J, Bowers MT, Jackson AT and Scrivens JH, (2002) J Am Chem Soc 13:499505.

25. www.indiana.edu/ nano/Software/mobcal.txt

26. Smith DP, Knapman TW, Campuzano I, Malham RW, Berryman JT, Radford SE, Ashcroft AE, (2009) Eur J Mass Spectrom 15:113-130.

27. McCullough B J, Kalapothakis J, Eastwood H, Kemper P, MacMillan D, Taylor K, Dorin J, Barran PE, (2008) Anal Chem 80:6336-6344.

28. Von Helden G, Hsu MT, Gotts N, Bowers MT, (1993) J Phys Chem, 97:8182-8192.

29. Shvartsburg AA, Jarrold MF, (1996) Chem Phys Lett 261:86-91.

30. Mesleh MF, Hunter JM, Shvartsburg AA, Schatz GC, Jarrold M F, (1996) J Phys Chem, 100:16082-16086.

31. Siu C, Guo Y, Saminathan IS, Hopkinson AC, Siu KWM, (2010) J Phys Chem 114:1204-1212.

32. Gaussian 09, Revision A.1, Frisch, M. J.; Trucks, G. W.; Schlegel, H. B.; Scuseria, G. E.; Robb, M. A.; Cheeseman, J. R.; Scalmani, G.; Barone, V.; Mennucci, B.; Petersson, G. A.; Nakatsuji, H.; Caricato, M.; Li, X.; Hratchian, H. P.; Izmaylov, A. 
F.; Bloino, J.; Zheng, G.; Sonnenberg, J. L.; Hada, M.; Ehara, M.; Toyota, K.;

Fukuda, R.; Hasegawa, J.; Ishida, M.; Nakajima, T.; Honda, Y.; Kitao, O.; Nakai, H.; Vreven, T.; Montgomery, Jr., J. A.; Peralta, J. E.; Ogliaro, F.; Bearpark, M.; Heyd, J. J.; Brothers, E.; Kudin, K. N.; Staroverov, V. N.; Kobayashi, R.; Normand, J.; Raghavachari, K.; Rendell, A.; Burant, J. C.; Iyengar, S. S.; Tomasi, J.; Cossi, M.; Rega, N.; Millam, J. M.; Klene, M.; Knox, J. E.; Cross, J. B.; Bakken, V.; Adamo, C.; Jaramillo, J.; Gomperts, R.; Stratmann, R. E.; Yazyev, O.; Austin, A. J.; Cammi, R.; Pomelli, C.; Ochterski, J. W.; Martin, R. L.; Morokuma, K.; Zakrzewski, V. G.; Voth, G. A.; Salvador, P.; Dannenberg, J. J.; Dapprich, S.; Daniels, A. D.; Farkas, Ö.; Foresman, J. B.; Ortiz, J. V.; Cioslowski, J.; Fox, D. J. Gaussian, Inc., Wallingford CT, 2009.

33. Valentine SJ, Conterman AE and Clemmer DE, (1999) J Am Chem Soc Mass Spectrom, 10:1188-1211.

34. Jurneczko EJ, Kalapothakis J, Campuzano IDG, Morris M, Barran PE, (2012) Anal Chem, 84:8524-8531.

35. Morsa D, Gabelica V, De Pauw E, (2011) Anal Chem 83:5775-5782. 


\section{Tables}

Table 1. Collision cross sections determined by DTIMS and TWIMS using TAAHs and peptides calibration standards.

\begin{tabular}{|c|c|c|c|c|}
\hline \multirow[t]{2}{*}{ Compound } & \multirow[t]{2}{*}{$m / \mathbf{z}$} & \multicolumn{3}{|c|}{ Experimental CCS/ $\AA^{\mathrm{a}}$} \\
\hline & & $\begin{array}{c}\text { TWIMS } \\
\text { (TAAHs) }\end{array}$ & $\begin{array}{c}\text { TWIMS } \\
\text { (Peptides) }\end{array}$ & Drift tube \\
\hline Ligand 1 & 323 & 120 & 113 & 109 \\
\hline Ligand 2 & 317 & 113 & 108 & 105 \\
\hline Ligand 3 & 269 & 103 & 97 & 94 \\
\hline L1Cu & 384 & 122 & 115 & 109 \\
\hline L2Cu & 378 & 116 & 110 & 104 \\
\hline L3Cu & 330 & 103 & 98 & 94 \\
\hline L1Zn & 385 & 123 & 117 & 110 \\
\hline L2Zn & 379 & 119 & 112 & 106 \\
\hline L3Zn & 331 & 105 & 100 & 97 \\
\hline
\end{tabular}

${ }^{\mathrm{a}}$ TWIMS data measured in nitrogen, DTIMS data measured in helium

Table 2. Theoretical collision cross sections calculated from X-ray and modelled structures using MOBCAL.

\begin{tabular}{ccccccc}
\hline Compound & \multicolumn{3}{c}{$\begin{array}{c}\text { MOBCAL (He) } \\
\text { X-ray CCS/A } \AA^{2}\end{array}$} & \multicolumn{3}{c}{ MOBCAL (He) } \\
& \multicolumn{2}{c}{ Modelled CCS/A ${ }^{2}$} \\
\hline PA & EHSS & TM & PA & EHSS & TM \\
Ligand 1 & 115 & 123 & 116 & 120 & 128 & 117 \\
Ligand 2 & 117 & 124 & 116 & 117 & 123 & 115 \\
Ligand 3 & 110 & 115 & 106 & 106 & 112 & 105 \\
L1Cu & 116 & 122 & 114 & 121 & 128 & 118 \\
L2Cu & 113 & 117 & 110 & 118 & 123 & 115 \\
\hline
\end{tabular}




\begin{tabular}{lcccccc}
\hline L3Cu & 105 & 108 & 101 & 107 & 112 & 105 \\
L1Zn & 118 & 124 & 118 & 122 & 129 & 119 \\
L2Zn & 113 & 117 & 114 & 119 & 124 & 115 \\
L3Zn & 103 & 107 & 101 & 108 & 113 & 106 \\
\hline
\end{tabular}

Table 3. Theoretical collision cross sections calculated from X-ray and modelled structures using MOBCAL with Siu's and Campuzano's parameters sets.

\begin{tabular}{lcccccccc}
\hline Compound & \multicolumn{4}{c}{ MOBCAL } & \multicolumn{4}{c}{ MOBCAL } \\
& \multicolumn{3}{c}{ X-ray CCS/ $\AA^{2}$} & \multicolumn{3}{c}{ Modelled CCS/ $\AA^{2}$} \\
& PA & EHSS & TM & TM & PA & EHSS & TM & TM \\
& 104 & 112 & 107 & 110 & 110 & 113 & 109 & 114 \\
\hline Ligand 1 & 107 & 112 & 107 & 112 & 107 & 111 & 106 & 113 \\
Ligand 2 & 99 & 100 & 97 & 102 & 97 & 99 & 97 & 102 \\
Ligand 3 & 107 & 112 & 104 & 111 & 112 & 114 & 110 & 116 \\
L1Cu & 104 & 110 & 101 & 108 & 109 & 112 & 106 & 113 \\
L2Cu & 96 & 98 & 92 & 99 & 99 & 100 & 97 & 103 \\
L3Cu & 109 & 113 & 108 & 114 & 113 & 114 & 111 & 116 \\
L1Zn & 104 & 110 & 107 & 112 & 110 & 113 & 106 & 113 \\
L2Zn & 95 & 99 & 92 & 99 & 100 & 100 & 98 & 103 \\
L3Zn & & & & & & & & \\
\hline
\end{tabular}




\section{Figures}

Fig 1 Chemical structures of ligand 1, ligand 2 and ligand 3

Fig 2 TWIMS ion mobility spectra of ligand L1 (left, $m / z$ 323.176) and the L1Cu (centre, $m / z$ 384.089) and L1Zn (right, $m / z$ 385.089) metal complexes

Fig 3 A comparison between the experimental data from DTIMS and TWIMS and the theoretical data from X-ray and modelled structures using the Siu parameters for $\mathrm{L} 2 \mathrm{Cu}$ complex. 